\title{
METODE PENCELUPAN NILAI BUDAYA DALAM PEMBELAJARAN BIPA DI POLITEKNIK NEGERI BALI
}

\author{
Ida Bagus Artha Adnyana \\ Jurusan Administrasi Niaga, Politeknik Negeri Bali, Bukit Jimbaran Bali, Denpasar 80361 \\ E-mail: arthaadnyana@pnb.ac.id
}

\begin{abstract}
The teaching of Indonesian to speakers of other languages (BIPA) student was very interesting Indonesian cultural values. That is very meaningful to the BIPA students to enrich principle of their life. This research aims to know the exact method used in the study of cultural value so that the BIPA students was expected to be pervading the culture. This research was conducted against the ten BIPA students in the class interest State Polytechnic of Bali year 2017/2018. Questionnaires and observations method is used in data collection. This method was aided by advanced participatory techniques. The data obtained are then analyzed using the equal methods. Based on the results of the BIPA students response to some of the methods tested can be concluded that $96.3 \%$ of respondents stated that the cultural value of the immersion method applied in State Polytechnic of Bali is very worthy to support the process of BIPA learning. There are several methods that are appreciated by the students, among others: guessing pictures, running dictation, observation, video documentation, immersion, and debate. Among these methods, the immersion is the most interesting one favored by the BIPA students. They can directly feel and experience the activity in their everyday life.
\end{abstract}

Keywords: immersion, culture, learning, BIPA

\begin{abstract}
Abstrak
Para pemelajar BIPA sangat tertarik dengan nilai-nilai budaya nusantara. Pemberian nilai budaya ini sangat berarti bagi pemelajar BIPA untuk mengayakan prinsip hidupnya. Penelitian ini bertujuan untuk dapat mengetahui metode yang tepat digunakan dalam pembelajaran nilai budaya sehingga pemelajar BIPA diharapkan dapat meresapi budaya tersebut. Penelitian ini dilakukan terhadap sepuluh mahasiswa pemelajar BIPA di kelas darmasiswa Politeknik Negeri Bali angkatan tahun 2017/2018. Metode kuesioner dan observasi (simak) digunakan dalam pengumpulan data. Metode ini dibantu dengan teknik lanjutan yaitu teknik simak libat cakap dan teknik simak bebas libat cakap. Data yang didapatkan kemudian dianalisis dengan menggunakan metode padan. Berdasarkan hasil tanggapan pemelajar BIPA terhadap beberapa metode yang diujicobakan dapat disimpulkan bahwa 96,3 \% responden menyatakan bahwa metode pencelupan nilai budaya yang diterapkan di Politeknik Negeri Bali ini sangat layak untuk mendukung proses pembelajaran BIPA. Ada beberapa metode yang diapresiasi oleh pemelajar BIPA, antara lain: tebak gambar, berlari sambil mengimla (running dictation), menyimak (observasi), dokumentasi video, pencelupan langsung (immersion), dan debat. Di antara metode tersebut, metode pencelupan langsung (immersion) paling digemari oleh pemelajar BIPA karena mereka secara langsung dapat merasakan dan mengalami dalam kehidupan seharihari.
\end{abstract}

Kata kunci: pencelupan, budaya, pembelajaran, BIPA 


\section{PENDAHULUAN}

Salah satu sisi ikutan belajar bahasa adalah juga berarti belajar budaya bahasa tersebut. Demikian juga yang terjadi pada pembelajaran bahasa Indonesia. Pengajaran bahasa Indonesia tidak bisa dilepaskan dari budaya Indonesia dan budaya lokal di mana bahasa tersebut dipelajari. Terlebih lagi pembelajaran bahasa Indonesia itu diperuntukkan bagi penutur asing (BIPA).

Zoetmulder mengungkapkan hubungan bahasa dan budaya sebagai perkembangan segala kemungkinan dan kekuatan kodrat, terutama kodrat dalam manusia, di bawah pembinaan akal budi (Poespowardojo, 1989). Ini berarti bahwa kebudayaan mencakup seluruh dinamika serta realisasinya menuju kesempurnaan atau kedewasaan. Sehubungan dengan realisasi bakat dan kemampuan manusia, kebudayaan juga menunjukkan pola-pola pemikiran serta tindakan tertentu yang terungkap dalam aktivitas kehidupan, termasuk aktivitas berbahasa. Pandangan ini diperkuat oleh Thanasoulas (2001) yang menyimpulkan bahwa kebudayaan dan komunikasi adalah dua hal yang tidak terpisahkan. Kebudayaan tidak mendikte siapa bisa berbicara kepada siapa, tentang apa, dan bagaimana komunikasi dilakukan.

Dalam hubungannya dengan mempelajari bahasa kedua, Kramsch (1993) juga menyatakan bahwa mempelajari budaya tidak bisa diartikan sebagai bagian terpisah dari bagianbagian integral pembelajaran bahasa seperti wicara, menyimak, membaca, dan menulis. Ini berarti bahwa para pengajar bahasa kedua harus melakukan lebih dari sekadar memonitor produksi linguistik di ruang kelas. Para pengajar bahasa kedua harus menyadari kerumitan dan banyaknya proses mediasi interkultural yang dialami para pemelajar bahasa kedua.
Salah satu konsep kehidupan universal yang diterapkan di Bali adalah konsep Trihita Karana (THK). THK mempunyai makna dan hakikat yang bersifat universal dan ada di setiap kitab suci agama-agama besar di dunia (Windia, 2007). Oleh karena itu, dalam pembumiannya ke dalam berbagai aspek kehidupan manusia di bumi agar tidak semata-mata dikaji atau dipahami menurut perspektif Hindu saja. Hal ini penting ditegaskan mengingat keberagaman budaya nusantara bersifat multikeimanan dan multibudaya. Dengan demikian dalam membumikan konsep Trihita Karana perlu diberi makna operasional dengan tidak membedabedakan agama, bahasa, warna kulit, dan bangsa karena perbedaan itu adalah kearifan Tuhan.

THK ini mengajarkan bahwa kebahagiaan akan tercapai apabila manusia mampu mengadakan hubungan yang harmonis dengan Tuhan (disebut unsur parhyangan), dengan alam atau lingkungan (unsur palemahan) dan hubungan dengan sesama manusia dalam masyarakat (unsur pawongan). Konsep ini pada dasarnya analog dengan sistem kebudayaan yang disebutkan oleh Koentjaraningrat (1993) sebagai suatu sistem yang memiliki elemen konsep atau nilai, subsistem sosial, dan subsistem artefak atau kebendaan.

Esensi pemahaman THK untuk mencapai kebahagiaan hidup melalui proses harmoni dan kebersamaan (Suamba dan Sutama, 2017; Purana, 2016). Konsep ini selanjutnya menyebabkan manusia Bali sangat kuat keterikatannya dengan desa adat atau masyarakat hukum adat tradisional yang dicirikan oleh berbagai kolektivitas kegiatan sosial-religius (Pitana, 1999). Sebagai suatu kebudayaan THK pada dasarnya bukanlah sesuatu yang statis, tetapi sebaliknya sebagai sesuatu yang dinamis, seirama dengan dinamika budaya kehidupan masyarakat. 
Untuk mengayakan pengalaman para pemelajar BIPA perlu diberikan pemahaman tentang budaya sehingga bahasa Indonesia yang dipelajarinya memiliki daya rekat yang lebih tinggi. Metode pembelajaran yang dipilih adalah metode pembelajaran aktif. Ketika pemelajar aktif, berarti mereka yang mendominasi aktivitas pembelajaran. Dengan cara seperti ini, maka pemelajar akan aktif menggunakan otak, baik untuk menemukan ide pokok dari materi pembelajaran, memecahkan persoalan, atau mengaplikasikan apa yang baru mereka pelajari ke dalam suatu persoalan yang ada dalam kehidupan nyata. Dengan belajar aktif, pemelajar turut serta dalam semua proses pembelajaran, tidak hanya melibatkan pikiran, akan tetapi juga melibatkan fisik. Dengan cara seperti itu, pemelajar akan merasa terlibat dalam suasana yang lebih menyenangkan sehingga hasil belajar dapat dimaksimalkan.

Belajar aktif adalah salah satu cara untuk mengikat informasi yang baru saja diterima oleh pengajar untuk selanjutnya disimpan dalam otak. Untuk dapat menyimpan dengan baik diperlukan beberapa tindakan seperti pengulangan informasi, mempertanyakan informasi, berbagi dengan orang lain, pengamatan, dan praktik langsung. Pertimbangan lain untuk menggunakan strategi pembelajaran aktif adalah adanya realita bahwa pemelajar mempunyai cara belajar yang berbeda-beda. Ada pemelajar yang lebih senang membaca, ada yang senang berdiskusi, bermain, dan ada juga yang senang praktik langsung. Inilah yang sering disebut dengan gaya belajar atau learning style (Zaini, 2002). Untuk membantu pemelajar agar maksimal dalam belajar, maka kesenangan dalam belajar itu sebisa mungkin diperhatikan. Untuk dapat mengakomodasi kebutuhan tersebut dapat dilakukan dengan menggunakan variasi strategi pembelajaran yang beragam dengan melibatkan indera belajar.

\section{METODE PENELITIAN}

Kajian ini bertujuan untuk mengetahui respons pemelajar terhadap metode pembelajaran aktif yang digunakan dalam belajar, khususnya dalam pencelupan nilai-nilai budaya dalam pembelajaran BIPA. Penelitian ini dilakukan terhadap sepuluh mahasiswa pemelajar BIPA di kelas darmasiswa Politeknik Negeri Bali angkatan tahun 2017/2018. Metode kuesioner dan observasi (simak) digunakan dalam pengumpulan data. Metode ini dibantu dengan teknik lanjutan yaitu teknik simak libat cakap dan teknik simak bebas libat cakap. Pada akhir pembelajaran pemelajar diberikan kuesioner untuk mengevaluasi respons terhadap metode yang digunakan. Data yang didapatkan kemudian dianalisis dengan menggunakan metode padan dan disajikan dengan metode deskriptif kualitatif.

\section{HASIL DAN PEMBAHASAN}

Ada beberapa metode pembelajaran aktif yang diujicobakan dalam pengintegrasian nilai budaya dalam pembelajaran BIPA. Metode-metode ini dipilih berdasarkan karakteristik pemelajar BIPA dan kemudahan materi tersebut disampaikan. Metode-metode yang digunakan dapat dijelaskan sebagai berikut.

\subsection{Tebak Gambar}

Metode tebak gambar dilakukan dengan kartu-kartu yang berisi gambar antara lain lingkungan alam (gunung, sungai, laut), tempat ibadah, jenis-jenis bentuk rumah atau bangunan, jenis-jenis alat musik. Tujuan metode pembelajaran ini untuk mengayakan kosa kata yang terkait dengan budaya dan lingkungan. Cara memainkannya dapat dilakukan dengan berpasangan. Yang satu menebak dan yang lainnya mengiyakan atau menolak. Pemenangnya adalah pemelajar 
yang tebakannya paling banyak benar. Pada akhir sesi pengajar dapat menjelaskan bagaimana masyarakat memaknai gunung sebagai hulu dan sumber kemakmuran, misalnya.

\subsection{Berlari sambil Mengimla (running dictation)}

Berlari sambil mengimla juga dilakukan secara berpasangan. Pengajar menyiapkan teks bacaan yang terkait dengan budaya, seperti yang terkait dengan pengairan (subak), tempat pemujaan, sejarah, tradisi. Teks bacaan ini ditempel di tembok di luar kelas. Salah seorang pelajar mondar-mandir membaca teks dan mengimlakan kepada pasangannya yang berada di dalam kelas. Pasangannya yang di dalam kelas ini menulis apa yang diimla ke dalam bentuk teks. Pemenangnya adalah pasangan yang paling cepat selesai dan tingkat kesamaannya paling tinggi dengan teks yang ditempelkan di luar tersebut. Teks yang digunakan ini juga selanjutnya dapat dibahas baik kosa kata, tata bahasa, dan budaya atau tradisi yang terkait dengan bacaan tersebut.

Contoh: Pura Goa Gajah

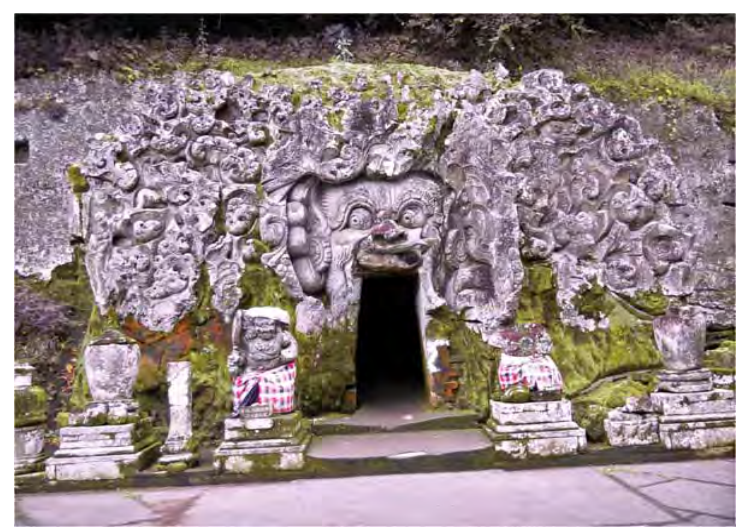

Gambar 1. Pura Goa Gajah

(sumber : Objek dan Daya Tarik Wisata Bali II, 1992:33)

Goa Gajah ditemukan pada tahun 1923. Nama Goa Gajah telah disebut di dalam kitab Nagarakertagama yang ditulis pada tahun 1365 M. Pada tahun 1954, ditemukan kembali kolam permandian di depan goa yang kemudian disusul dengan perbaikan patung pancuran yang semula terletak di depan goa dalam keadaan tidak lengkap. Ciri historis Goa gajah dapat dibagi menjadi dua bagian.

Goa gajah di kalangan penduduk setempat lebih dikenal dengan nama Pura Goa. Pura ini terletak di sebelah barat Desa Bedahulu, Kecamatan Blahbatuh, Kabupaten Gianyar, kira-kira 27 km dari Denpasar. Kunjungan ke pura ini dapat dilakukan dengan mudah karena letaknya hanya beberapa meter di bawah jalan raya Tampaksiring. Pura ini dibangun di lembah sungai Petanu dengan panorama alam yang indah.(diadaptasi dari Objek dan Daya Tarik Wisata Bali II, 1992)

Teks di atas juga dapat dijadikan acuan untuk belajar tata bahasa khususnya dalam pembentukan pasif di- dan ter-.

\subsection{Metode Simak (Observasi)}

Metode simak ini dapat digunakan untuk mengamati secara langsung aktivitas masyarakat pemakai bahasa. Ada tiga aktivitas yang diujicobakan. Para pemelajar BIPA dapat dibagi ke dalam beberapa kelompok untuk memilih masing-masing aktivitas. Pertama, aktivitas masyarakat terhadap lingkungan khususnya tumbuh-tumbuhan. Di Bali usaha pelestarian pohon dilakukan dengan memberi kain selimut "poleng” terhadap tumbuh-tumbuhan yang ingin dilindungi, seperti gambar di bawah ini.

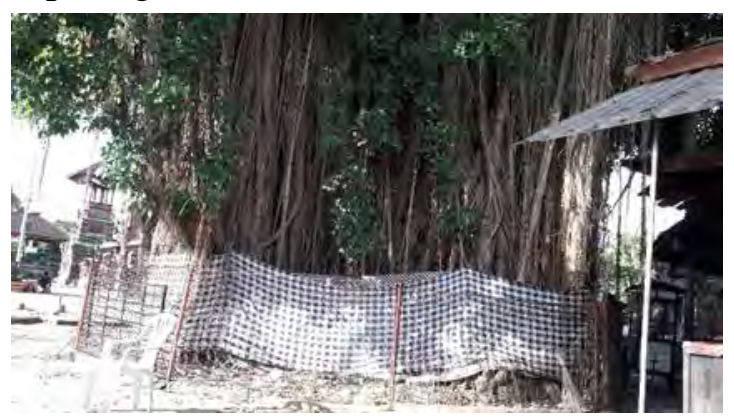

Gambar 2. Kain Selimut "poleng”

(sumber: Dokumentasi penulis, 2017)

Kecintaan masyarakat terhadap tanaman dilindungi dengan selimut tersebut dan tidak seorang pun berani menebangnya. Akhirnya, perlindungan terhadap pohon ini juga berdampak religius. Beberapa kendaraan yang lewat membunyikan klakson pertanda mohon 
izin akan lewat karena tempat tersebut diyakini menjadi keramat dan ada penghuninya. Aturan lainnya terhadap pelestarian tanaman adalah adanya aturan tidak tertulis bahwa pada hari Minggu tidak boleh memotong bambu. Aturan ini juga mengindikasikan bahwa bambu merupakan tanaman yang sangat penting dalam kehidupan masyarakat Bali. Di samping itu, orang Bali juga secara khusus memuja tumbuh-tumbuhan pada hari Tumpek Uduh/Pengatag yaitu pada hari Sabtu wuku Wariga.

Aktivitas kedua yang menjadi kajian adalah pembelajaran perilaku. Sejak kecil masyarakat Hindu diajarkan berterima kasih kepada Tuhan sebelum makan. Aktivitas ini disebut Saiban. Saiban adalah korban suci dalam skala kecil berupa miniatur apa yang kita makan dipersembahkan juga sebelumnya kepada Tuhan. Ini dilakukan sebagai rasa terima kasih karena hari tersebut kita bisa makan.

Aktivitas ketiga, pelajar diminta mengamati secara langsung bagaimana masyarakat Bali menata bangunan di pekarangannya. Di mana menempatkan tempat suci, dapur, lumbung, bangunan untuk tempat tidur anak gadis (meten), bangunan untuk upacara dan kematian (bale dangin). Semua ini menggunakan aturan khusus agar rumah yang ditempati terasa nyaman dan tenteram. Di bawah ini disajikan aturan tradisonal bagaimana orang Bali memosisikan letak-letak bangunan di pekarangannya.

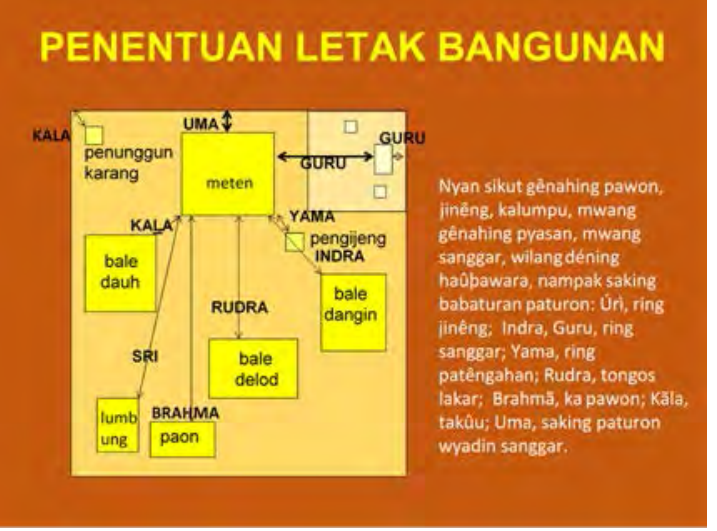

Gambar 3. Tata letak bangunan masyarakat Bali (Sumber : Susanto, 2017)
Penerapan ketiga metode ini dapat dibantu dengan metode wawancara terstruktur untuk mengayakan kosa kata baru dan nilai-nilai budaya yang terkandung di dalamnya. Pemelajar ditugaskan untuk mewawancarai pandangan orang terhadap ketiga aktivitas tersebut sehingga nilai-nilai yang terkandung di dalamnya dapat dipahami.

\subsection{Metode Dokumentasi dengan Video}

Dokumentasi dengan video dapat dijadikan satu model pembelajaran untuk menanamkan nilai-nilai budaya yang dibangun dalam hubungannya manusia dengan manusia (pawongan). Pemelajar ditugaskan membuat video tentang bagaimana masyarakat Bali menjadikan balai banjar sebagai pusat belajar dan berbagai aktivitas baik tradisional maupun modern. Semua kegiatan yang dilakukan secara informal di banjar meliputi beberapa aktivitas antara lain; belajar menari, menabuh, bernyanyi tradisional (shanti), posyandu, kegiatan lansia, rapat, bahkan senam modern untuk ibu-ibu PKK. Contoh video: Banjar sebagai Pusat Belajar(C video 1).

\subsection{Metode (Immersion)}

Pencelupan dilakukan dengan melibatkan secara langsung pelajar dalam aktivitas yang mau didalami. Ada tiga pilihan yang diberikan, yaitu: menari kecak, memasak tradisional (cooking class), dan membuat canang sari (salah satu jenis sarana upakara yang paling sederhana). Pemelajar dipersilakan memilih aktivitas yang ingin ditekuni. Mereka akan dibimbing oleh pengajar yang profesional di bidangnya. 


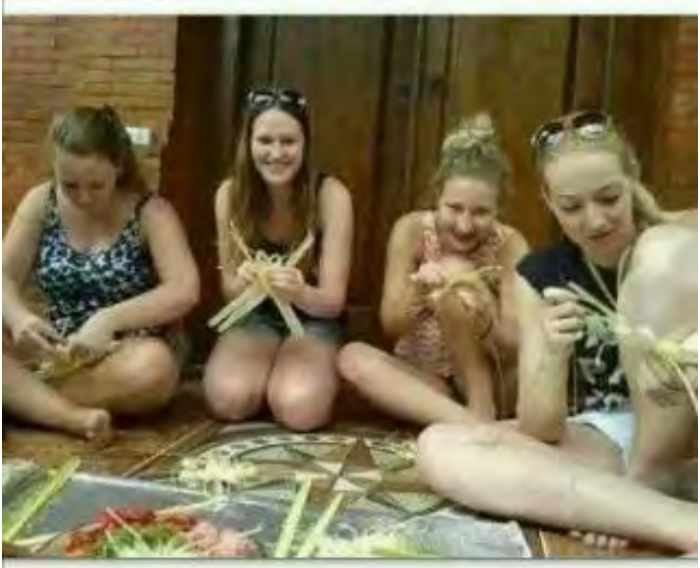

Gambar 4. Pemelajar BIPA Belajar membuat canang sari

(Sumber: Dokumentasi BIPA)

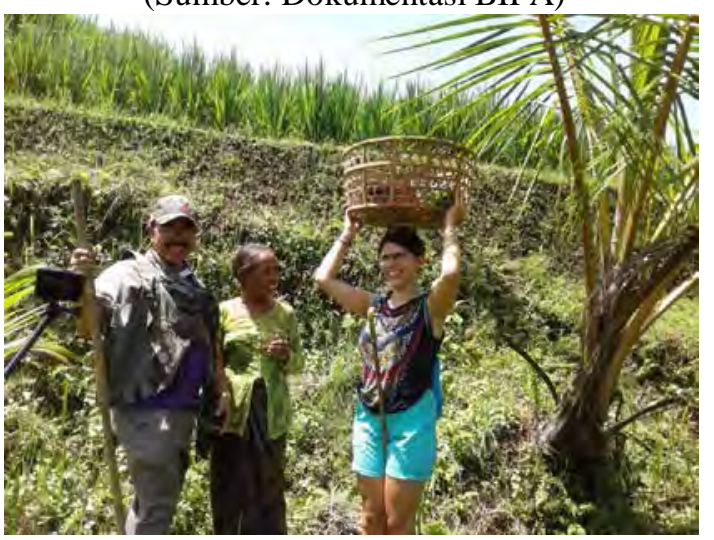

Gambar 5. Pemelajar BIPA Terlibat Kegiatan Sehari-hari

(Sumber: Dokumentasi BIPA)

\subsection{Metode Debat}

Metode ini dilakukan untuk memberi penilaian secara kritis dan tajam terhadap suatu fenomena yang mereka hadapi di masyarakat. Pemelajar dibagi ke dalam dua kelompok. Ada kelompok pro (yang mendukung tema yang dikritisi) dan ada kelompok kontra (yang menyanggah). Setiap kelompok terdiri dari 3 orang. Tiap-tiap orang diberikan waktu selama 2 menit untuk bertahan terhadap pendapatnya dengan mengungkapkan secara kritis dan tajam argumenargumennya sesuai dengan pengalamannya tentang topik yang dibahas. Dalam debat ini juga secara otomatis ada pembelajaran: pelafalan (spelling), kefasihan (fluency), pengayaan kosa kata (vocabulary), dan tata bahasa (grammar).

\subsection{Pembahasan}

Pengintegrasian materi budaya dalam pembelajaran BIPA sangat menarik minat pemelajar BIPA dalam mengayakan pemahamannya tentang budaya bahasa yang dipelajari. Penambahan wawasan di bidang budaya meyakinkan mereka terhadap nilai falsafah hidup, keberagaman, kebermaknaan fungsi, kerja sama, keberimbangan, dan tatanan proses untuk dapat menjalani hidup secara tenteram dan harmonis untuk mencapai kebahagiaan. Metode pembelajaran aktif yang diujicobakan untuk mendukung penanaman nilai budaya ini juga mendapat respons yang positif karena dalam proses penyajiannya mereka belajar dan mengalami sehingga pembelajaran menjadi lebih bermakna. Dalam hal ini pemelajar mengontekstualkan materi dengan dunia nyata sehingga mampu mendorong mereka untuk menghubungkan antara pengetahuan awal yang mereka miliki dengan penerapannya di dunia nyata. Tabel 1 berikut ini menyajikan respons mereka terhadap metode yang diujicobakan. 
Tabel 1. Respons Pelajar terhadap Metode Pengajaran Budaya dalam Pengajaran BIPA

\begin{tabular}{|c|c|c|c|c|c|c|c|c|c|c|c|}
\hline \multirow[t]{2}{*}{ No. } & \multirow{2}{*}{$\begin{array}{l}\text { Metode yang } \\
\text { Digunakan }\end{array}$} & \multirow{2}{*}{$\begin{array}{l}\text { Aktivitas yg } \\
\text { diujicobakan }\end{array}$} & \multicolumn{5}{|c|}{ Skala Penilaian } & \multirow[t]{2}{*}{$\Sigma \mathrm{X}$} & \multirow[t]{2}{*}{$\mathrm{n}$} & \multirow[t]{2}{*}{$\%$} & \multirow[t]{2}{*}{ Kriteria } \\
\hline & & & 1 & 2 & 3 & 4 & 5 & & & & \\
\hline 1. & Tebak gambar & $\begin{array}{l}\text { Menebak gambar: alam, } \\
\text { rumah, tempat suci }\end{array}$ & 0 & 0 & 0 & 4 & 6 & 47 & 50 & 92 & $\begin{array}{c}\text { Sangat } \\
\text { layak }\end{array}$ \\
\hline 2. & $\begin{array}{l}\text { Berlari sambil } \\
\text { mengimla }\end{array}$ & $\begin{array}{l}\text { Teks bacaan sejarah: } \\
\text { Goa Gajah }\end{array}$ & 0 & 0 & 0 & 1 & 9 & 49 & 50 & 98 & $\begin{array}{c}\text { Sangat } \\
\text { layak }\end{array}$ \\
\hline 3. & $\begin{array}{l}\text { Simak } \\
\text { (Observasi) }\end{array}$ & \begin{tabular}{ll}
\multicolumn{2}{l}{ Mengamati aktivitas: } \\
$\checkmark$ & pohon \\
& berselimut \\
$\checkmark$ & upacara Saiban \\
$\checkmark$ & penataan \\
& bangunan \\
& tradisional \\
\end{tabular} & 0 & 0 & 0 & 2 & 8 & 48 & 50 & 96 & $\begin{array}{c}\text { Sangat } \\
\text { layak }\end{array}$ \\
\hline 4. & $\begin{array}{l}\text { Pembuatan } \\
\text { Video }\end{array}$ & 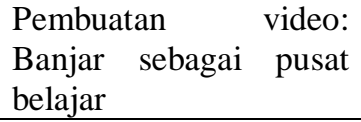 & 0 & 0 & 0 & 2 & 8 & 48 & 50 & 96 & $\begin{array}{l}\text { Sangat } \\
\text { layak }\end{array}$ \\
\hline 5. & $\begin{array}{l}\text { Pencelupan } \\
\text { (immersion) }\end{array}$ & $\begin{array}{ll}\checkmark & \text { Menari Kecak } \\
\checkmark & \text { Memasak } \\
& \text { tradisonal } \\
\checkmark & \text { Mengukir buah } \\
\checkmark & \text { Membuat Canang } \\
& \text { Sari }\end{array}$ & 0 & 0 & 0 & 0 & 10 & 50 & 50 & 100 & $\begin{array}{c}\text { Sangat } \\
\text { layak }\end{array}$ \\
\hline 6. & Debat & 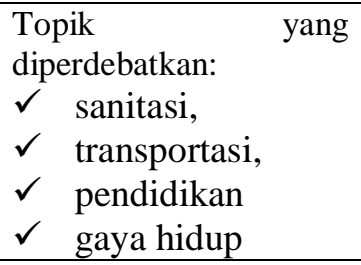 & 0 & 0 & 0 & 2 & 8 & 48 & 50 & 96 & $\begin{array}{c}\text { Sangat } \\
\text { layak }\end{array}$ \\
\hline & & Persent & $d^{-1}$ & & & & & & & 96,3 & $\begin{array}{r}\text { Sangat } \\
\text { layak }\end{array}$ \\
\hline
\end{tabular}

(Sumber: data diolah)

Secara umum hampir semua metode yang diujicobakan menarik perhatian pemelajar BIPA. Hal ini dibuktikan dengan rentangan respons mereka semuanya berkisar pada nilai baik dan sangat baik dengan nilai rata-rata sebesar 96,3\%. Bahkan untuk metode pencelupan (immersion) semua pemelajar merespons dengan sangat baik.

\section{KESIMPULAN DAN SARAN}

Respons pemelajar BIPA terhadap penggunaan metode pembelajaran aktif dalam mengintegrasikan nilai-nilai budaya berada pada kualifikasi sangat baik dengan nilai rata-rata 96,3 \%. Ini berarti metode yang digunakan sangat layak untuk mendukung pembelajaran BIPA

\section{DAFTAR PUSTAKA}

Duranti, A. (1997). Linguistic Anthropology. Cambridge: Cambridge University Press.

Ghazali, A. Syukur. (2013). Pembelajaran Keterampilan Berbahasa. Bandung: PT Refika Aditama.

Koentjaraningrat. (1993). Kebudayaan, Mentalitas, dan Pembangunan. Jakarta: Gramedia Pustaka Utama. 
Kramsch, C. (1993). Context and Culture in Language Teaching. Oxford: Oxford University Press

Mahsun.(2005). Metode Penelitian Bahasa. Jakarta: PT Raja Grafindo Persada.

Pitana, I Gede. (1999). Pelangi Pariwisata Bali. Denpasar: Bali Post.

Poespowardojo, Soerjanto. (199)3. Strategi Kebudayaan. Jakarta: Gramedia.

Purana, I Made. (2016). “Pelaksanaan Tri Hita Karana dalam Kehidupan Umat Hindu”. Jurnal Kajian Pendidikan Widya Accarya, FKIP Universitas Dwijendra, Maret 2016, 69.

Suamba, Ida Bagus and I Ketut Sutama. (2017). "Materiality and Spirituality in Bali Tourism: An Ethical Reflection on the Tri-Hita-Karana”. International Journal of Applied Sciences in Tourism and Events, Vol 1 no.1 (2017): June 2017, 73

Sudaryanto. (2016). Metode dan Aneka Teknik Analisis Bahasa. Jogyakarta: Sanata Dharma University Press.

Susanta, I Nyoman. (2017). Rancangan Tapak. Denpasar: Universitas Udayana.

Thannasoulas, D. (2001). "The Importance of Teaching Culture in the Foreign Language Classroom" from

http:/radicalpedagogy.icaap.org/cont ent/issu3_3.

Windia, Wayan dan Ratna Komala Dewi. (2007). Analisis Bisnis yang Berlandaskan Trihita Karana. Denpasar: Universitas Udayana.

Zaini, Hisyam dkk.(2002). Strategi Pembelajaran Aktif di Perguruan Tinggi. Jogyakarta: Center for Teaching Staff Development (CTSD) IAIN Sunan Kalijaga 